\title{
Aplicación de protocolos de control de calidad en equipos de fluoroscopia en las ciudades de Tunja (Boyacá) y Bogotá
}

\section{Application of quality control protocols for fluoroscopy equipment in the cities of Tunja (Boyacá) and Bogotá}

Mercy Natalia González Sánchez, Hernán Olaya Dávila ${ }^{1}$

Citación: M. N. González Sánchez y H. Olaya Dávila, “Aplicación de protocolos de control de calidad en equipos de fluoroscopia en las ciudades de Tunja (Boyacá) y Bogotá", Revista Investigaciones y Aplicaciones Nucleares, n. $^{\circ}$ 3, pp. 12-27, 2019. https://doi.org/10.32685/2590-7468/invapnuclear.3.2019.507

Recibido: 16 de septiembre de 2019

Aceptado: 18 de diciembre de 2019

Publicado en línea: 30 de diciembre de 2019

Doi: https://doi.org/10.32685/2590

7468/invapnuclear.3.2019.507

Palabras clave: fluoroscopia, control de calidad, fantomas, angiografía.

\section{RESUMEN}

La obtención de imágenes de calidad en fluoroscopia depende, entre otros factores, de la habilidad del tecnólogo, del procedimiento radiográfico y, en especial, del desempeño del equipo utilizado. Para este último se han desarrollado diferentes protocolos de control de calidad que establecen un conjunto de pruebas para evaluar diferentes parámetros de calidad de la imagen y de la dosis recibida por el paciente. La realización de estas pruebas requiere de equipos detectores de radiación para evaluar los parámetros eléctricos y la cantidad de radiación recibida por el paciente, así como fantomas que permiten simular al paciente. Estos dispositivos son muy costosos y no tienen oferta en el mercado nacional, por lo que se evaluó el desempeño de los equipos de varios centros médicos ubicados en Tunja (Boyacá) y Bogotá, D. C., usando prototipos de fabricación nacional bajo las recomendaciones de la Asociación Americana de Física en Medicina, AAPM por sus siglas en inglés, para fantomas craneales en adultos y con base en relaciones antropométricas. Ejecutados los protocolos, con los prototipos de fantomas se encontró que todos los equipos cumplen con los límites de tolerancia y niveles de referencia establecidas en ambos protocolos, con la excepción del equipo telecomandado, que no cumplió con la tolerancia para resolución espacial. La mejor calidad de imagen de los equipos evaluados, en términos generales, se obtiene del angiógrafo, y el que menor dosis entrega al paciente es el del fabricante Philips. Adicionalmente, se logró establecer y documentar por primera vez la configuración específica para el desarrollo de las pruebas de control de calidad en equipos de angiografía.

\section{ABSTRACT}

Obtaining quality images in fluoroscopy depends, among other factors, on the skill of the technologist, the radiographic procedure and, especially, the performance of the equipment used. Regarding equipment performance, various quality control protocols have been developed that establish a set of tests to evaluate different parameters related to image quality and the dose received by the patient. The execution of these tests requires radiation detection equipment to evaluate electrical parameters and the quantity of radiation received by the pa-

${ }^{1}$ Servicio Geológico Colombiano

Email de correspondencia: holaya@sgc.gov.co 
Keywords: fluoroscopy, quality control, phantoms, angiography tient as well as phantoms that allow for simulation of patients. These devices are quite expensive and are not available in the domestic market. Therefore, the performance of the equipment of several medical centers located in Tunja (Boyacá) and Bogotá, Capital District, was evaluated using prototypes manufactured domestically according to the recommendations of the American Association of Physicists in Medicine (AAPM) for skull phantoms in adults and based on anthropometric relationships. Execution of quality control protocols with the phantom prototypes indicated that all of the equipment performed in accordance with the tolerance limits and reference levels established in both protocols, with the exception of remote control equipment, which did not exhibit the desired spatial resolution tolerance. In general, among the evaluated equipment, the angiograph produced the best image quality, and the one that delivered the lowest dose to the patient was manufactured by Philips. Additionally, we established and documented for the first time a specific configuration for the development of quality control tests for angiography equipment.

\section{INTRODUCCIÓN}

$\mathbf{L}$ a fluoroscopia es la obtención de imágenes diagnósticas en tiempo real. Los fotones producidos en un tubo de rayos $\mathrm{X}$ atraviesan el tejido humano; parte de los fotones incidentes interactúan con el paciente, mientras que los demás llegan al detector. Estos últimos aportan información sobre la anatomía del paciente, que es mostrada en una pantalla de televisión.

La imagen formada es construida en cada punto a partir del número de fotones que llegan al detector sin interactuar con el paciente. Este número depende del número $\mathrm{Z}$ promedio y la densidad electrónica del material absorbente, así como de la energía de los fotones incidentes. La intensidad vista desde el detector en cada punto se expresa mediante esta ecuación:

$$
N=N_{0} e^{-\mu x}
$$

en donde:

$N_{0}$ es el número de fotones a la entrada del detector en ausencia del paciente.

$N$ es el número de fotones a la entrada del detector estando presente el paciente.

$\mu$ es el coeficiente de atenuación lineal, que depende del número atómico promedio, la densidad del material absorbente y la energía de los fotones incidentes.

$x$ es el espesor del material atenuante.
Con el fin de obtener una buena calidad de imagen con la menor dosis posible de radiación es necesario tener en cuenta los siguientes factores:

1. El área del campo de irradiación incidente no debe ser mucho más grande que el área de la superficie del detector, con el fin de no suministrar radiación en regiones innecesarias.

2. Usar la energía más apropiada de los fotones incidentes de forma que las diferencias de absorción en distintas regiones de la estructura que se quiere observar sean suficientes para obtener un buen contraste de la imagen. Para esto es necesario variar la diferencia de potencial en el tubo de rayos $\mathrm{X}$.

3. Limitar el número de fotones de baja energía que pueden entregar dosis al paciente, pero que tienen una baja probabilidad de llegar al detector, algo que se logra mediante el uso de filtros.

4. Restringir las tasas de dosis al paciente de acuerdo a su contextura, para evitar riesgos radiobiológicos.

5. Cuantificar la imagen. Esto se hace con el objetivo de proporcionarle al médico una buena calidad de imagen para obtener un diagnóstico exacto del paciente o para valorar la respuesta a algún tratamiento.

En Colombia, la Resolución 482 de febrero de 2018, del Ministerio de Salud y Protección Social [1], exige que los equipos emisores de radiación ionizante de uso médico sean sometidos a controles bienales de calidad, pero también se deben realizar estudios en las barreras estructurales de las instalaciones; denominados cálculos de blindajes para 
obtener licencia de operación, para obtener licencia de operación, tema que se ha tomado como objetivo de este trabajo. Dicha norma se ha ido implementando en equipos convencionales, como tomógrafos computarizados, mamógrafos, equipos de densitometría ósea y radiología dental, entre otros. El personal autorizado (profesionales con especialización en física médica o física radiológica) para realizar el control de calidad en los diferentes equipos deben regirse por los protocolos y normas establecidos por distintos países, como, por ejemplo, el Protocolo Español de Control de Calidad en Radiodiagnóstico (PECCR) [2], la Comisión Internacional de Protección Radiológica (ICRP), la Agencia Internacional de Energía Atómica (IAEA), el Arcal XLIX [3] y la Asociación Americana de Física en Medicina (AAPM). En el caso de los equipos fluoroscópicos, existe un procedimiento general de evaluación reflejado en los protocolos nombrados anteriormente; sin embargo, en la bibliografía no hay un protocolo detallado para equipos de angiografía digital, dada la aplicación particular, en rangos de energía y resolución espacial. Por tal razón, es importante tener una propuesta de protocolo de control de calidad en angiografía, en la que se especifiquen las pruebas que deben realizarse con instrumentación nueva, como la que posee el Laboratorio de Radiaciones Nucleares de la Universidad Pedagógica y Tecnológica de Colombia (UPTC).

En el mercado de nuestro país no existen herramientas de control de calidad que posibiliten realizar una evaluación integral del desempeño de un angiógrafo. Como estas herramientas son costosas en otros países, la razón de este trabajo es llegar a la fabricación de dichos objetos de prueba y crear prototipos propios que tengan el mismo desempeño y la misma calidad que los ofertados en el extranjero, para poder validar el desempeño de los simuladores físicos.

Las pruebas de control de calidad se hacen con el fin de verificar el desempeño adecuado de los equipos fluoroscópicos (arco en $\mathrm{C}$, telecomandado y angiógrafo) utilizados en prácticas de intervención médica. Para sustituir satisfactoriamente a los pacientes de anatomía promedio se construyen simuladores físicos (fantomas), que permiten atenuar y dispersar la radiación. Los fantomas son dispositivos que están construidos según las recomendaciones de la Asociación Americana de Física en Medicina (AAPM). Se elaboran dos simuladores de la región anatómica craneal (pediátrico y adulto) para evaluar el sistema de control automático de exposición (CAE). En el diseño y construcción del fantoma para angiografía cerebral se determinan las dimensiones con base en las medidas antropométricas aportadas por estudios que se han realizado en la Universidad Nacional de Colombia, sede de Bogotá, que ofrecen con exactitud las medidas promedio de extremidades, cabeza, cuello y tórax de adultos y niños, así como su peso. A partir de esto se podrá obtener el respectivo fantoma [4].

Además del simulador físico se utilizan objetos de prueba para medir parámetros como la resolución espacial y el rendimiento de bajo y alto contraste de la imagen. Estas herramientas son posicionadas contra el haz de rayos $\mathrm{X}$ para la evaluación respectiva. A partir de los resultados obtenidos se realiza una comparación con las tolerancias permitidas en los protocolos existentes, para verificar que los equipos cumplen con los estándares de control de calidad.

\section{ASPECTOS GENERALES}

En la fluoroscopia, los fotones atraviesan el tejido humano y son detectados para obtener una imagen que permitirá al médico determinar el diagnóstico del paciente. Cuando el fotón interactúa con el medio puede absorberse, transmitirse o dispersarse cambiando su dirección de desplazamiento. Los tres procesos por los que los fotones entregan su energía a la materia son el efecto fotoeléctrico, la dispersión Compton y la producción de pares. Los equipos fluoroscópicos que se utilizaron para el desarrollo de este trabajo manejan rangos de energía de rayos X de entre 50 y $150 \mathrm{keV}$. Por lo tanto, los dos tipos de interacciones que predominan son el efecto fotoeléctrico y la dispersión Compton [5].

Efecto fotoeléctrico. Este tipo de interacción ocurre cuando un electrón unido a un átomo absorbe un fotón [6]. El electrón orbital se expulsa con energía cinética $E_{K}$ y toma el nombre de fotoelectrón.

La energía cinética $E_{K}$ del fotoelectrón expulsado es igual a la energía del fotón incidente hv, menos la energía de enlace del electrón orbital.

$$
E_{K}=h v-E_{B}(1)
$$

En la emisión de un fotoelectrón se origina una vacante ocupada por un electrón de una capa superior. La energía de 
transición se emite como un fotón característico (fluorescencia). Cuando la energía del fotón es mayor que la energía de enlace en la capa $\mathrm{K}\left(E_{B}\right)$, el $80 \%$ de las absorciones fotoeléctricas ocurren con electrones de la capa K, y $20 \%$ ocurre con los electrones de capas superiores [7].

Efecto Compton. La interacción ocurre cuando un fotón con energía $h v$ y momento $h v / c$ choca con un electrón estacionario y libre. Luego de la colisión, el fotón se dispersa en un ángulo $\theta$ con energía $h v^{\prime}$ y momento $h v^{\prime} / c$. El electrón retrocede en un ángulo $\phi$ con energía $E_{e}$ total y momento $P_{e}$.

$$
\begin{gathered}
E_{e}=m_{e} c^{2}+E_{K}(2) \\
P_{e}=c^{-1} \sqrt{E_{K}\left(E_{K}+2 m_{e} c^{2}\right)}(3)
\end{gathered}
$$

Por conservación de energía, usando series de Taylor y aproximaciones clásicas para la energía cinética, se tiene que la energía del fotón dispersado en función de la energía del fotón incidente $h v$ y el ángulo de dispersión $\theta$ es:

$$
h v^{\prime}=h v\left(\frac{1}{1+\varepsilon(1-\cos \theta)}\right)(4)
$$

donde

$$
\varepsilon=\frac{h v}{m_{e} c^{2}}
$$

La energía cinética del electrón en retroceso, que depende de la energía del fotón incidente y el ángulo del fotón dispersado [7], es:

$$
E_{K}=h v-h v\left(\frac{1}{1+\varepsilon(1-\cos \theta)}\right)
$$

La fluoroscopia es una técnica que genera imágenes con rayos $\mathrm{X}$ en tiempo real [8], lo que es útil para el médico, debido a la producción de una imagen continua que permite observar órganos en movimiento dentro de un paciente o el flujo de un medio de contraste a través de los vasos sanguíneos. El sistema fluoroscópico consta de dos componentes principales, generalmente alineados: un tubo de rayos $\mathrm{X}$, encargado de emitir haces de fotones, y el sistema de detección. Los fotones de rayos $\mathrm{X}$ que atraviesan al paciente interactúan con el sistema de detección (intensificador de imagen o panel plano), y generan una imagen que es procesada y mostrada en una cámara de televisión. Los equipos fluoroscópi- cos modernos contienen medidores de producto dosis-área, filtración automática, fluoroscopia pulsada y sistemas de control automático de exposición (CAE), de manera que los parámetros de tensión y corriente se ajustan de acuerdo al modo de imagen (fluoroscopia baja, normal o alta), al campo de visión y al grosor del paciente [9].

En este trabajo se evalúan equipos usados en radiología intervencionista (fluoroscópicos), como el telecomandado mostrado en la figura 1, dos angiógrafos mostrados en las figuras 8 y 9, y adicionalmente se estudian dos arcos en $\mathrm{C}$, que se pueden observar en las figuras 2 y 3 , ubicados en diferentes centros hospitalarios de Boyacá y Cundinamarca.

\subsection{Equipos telecomandados}

Tabla 1. Especificaciones del equipo telecomandado

\begin{tabular}{lc}
\hline \multicolumn{1}{c}{ Servicio } & Relecomandado de marca Toshiba \\
\hline & Equipo \\
\hline Modelo del equipo & DBZK-HGHEAD \\
Serie del equipo & 99A09Z2361 \\
Marca del tubo & Toshiba \\
Modelo del tubo & BLF-15B \\
Serie del tubo & J3A09X2761 \\
\hline & Datos técnicos del equipo \\
\hline Kilovoltaje máximo & $150 \mathrm{kVp}$ \\
Corriente máxima de tubo & $4 \mathrm{~mA}$ \\
Filtración mínima & $1,2 \mathrm{~mm} \mathrm{Al} \mathrm{a} \mathrm{70} \mathrm{kV}$ \\
Filtración total & $2,5 \mathrm{~mm} \mathrm{Al} \mathrm{a} \mathrm{70} \mathrm{kV}$ \\
Potencia del tubo & $10,5 \mathrm{~W}$ \\
Número de monitores & 2 \\
Modos de operación & Radio/fluoro \\
\hline & Uso \\
\hline Los equipos telecomandado se utilizan como guía para el estudio convencional \\
contrastado en urografías, uretrocistografía, del tracto esófago-gastrointestinal. \\
También es utilizado como guía en procedimientos de radiología. \\
\hline
\end{tabular}

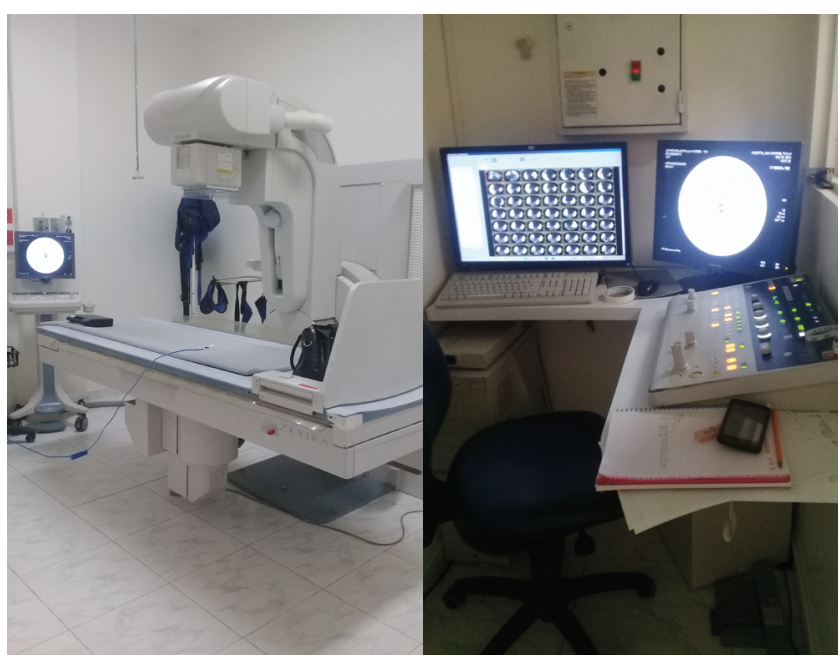

Figura 1. Equipo Telecomandado Toshiba 


\subsection{Arco en C}

Tabla 2. Especificaciones del Arco en C Philips

\begin{tabular}{lc}
\hline \multicolumn{1}{c}{ Servicio } & Rquipo \\
\hline Modelo del equipo & BV Pulsera \\
$\begin{array}{l}\text { N. }^{0} \text { del modelo del equipo } \\
\text { Serie del equipo }\end{array}$ & 718095 \\
Marca del tubo & 469 \\
Serie del tubo & PHILIPS \\
\hline & 22042 \\
\hline Kilovoltaje máximo & Datos técnicos del equipo \\
Corriente máxima de tubo & $120 \mathrm{kVp}$ \\
Frecuencia & $100 \mathrm{~mA}$ \\
Filtración agregada & $50 / 60 \mathrm{~Hz}$ \\
Filtración inherente & $3,0 \mathrm{~mm} \mathrm{Al}+0,1 \mathrm{mmCu}$ \\
\hline Fluoroscopia continua: & $1,0 \mathrm{Al} \mathrm{eq.}$ \\
Rango de voltaje & \\
Rango de corriente en fluoro & 40 a $120 \mathrm{kV}$ \\
de dosis baja & $0,10 \mathrm{a} 8,3 \mathrm{~mA}$ \\
Rango de corriente en fluoro & \\
de alta definición & 0,24 a $20,0 \mathrm{~mA}$ \\
Fluoroscopia pulsada: & 40 a $120 \mathrm{kV}$ \\
Rango de voltaje & $0,4-12 \mathrm{~mA}$ \\
Rango de corriente pico & Uso \\
\hline
\end{tabular}

Es un sistema de fluoroscopia móvil que se utiliza en procedimientos quirúrgicos e intervencionistas para capturar la anatomía en movimiento y ver dentro del paciente. Los procedimientos e intervenciones son procedimientos cardiovasculares, cirugía ortopédica, cirugía abdominal, procedimientos neuroquirúrgicos y cirugía torácica.

Tabla 3. Especificaciones del arco en C Siemens

\begin{tabular}{lc}
\hline \multicolumn{1}{c}{ Servicio } & \multicolumn{1}{c}{ Radiodiagnóstico } \\
\hline Modelo del equipo & Aquipo \\
N. ${ }^{0}$ del modelo del equipo & 08079233 \\
Serie del equipo & 25036 \\
Marca del tubo & Siemens \\
N. ${ }^{0}$ del modelo del tubo & 07721710 \\
Serie del tubo & 9373 \\
Fecha de fabricación & Septiembre de 2014 \\
\hline & Datos técnicos del equipo \\
\hline Kilovoltaje máximo & $110 \mathrm{kVp}$ \\
Corriente máxima de tubo & $23 \mathrm{~mA}$ \\
Rango de mAs ${ }^{<>}$ & $1-150 \mathrm{mAs}$ \\
Filtración agregada & $1,5 \mathrm{~mm}$ Al-75 kV \\
Potencia máxima del tubo & $2,3 \mathrm{~kW}$ a $100 \mathrm{kVp}$ \\
Tiempo de exposición & $5-10 \mathrm{~s}$ \\
Número de monitores & 2 \\
Modos de operación & Radio/fluoro \\
\hline
\end{tabular}

Es un sistema de fluoroscopia móvil que se utiliza en procedimientos quirúrgicos e intervencionistas para capturar la anatomía en movimiento y ver dentro del paciente. Estos son los procedimientos e intervenciones: procedimientos cardiovasculares, cirugía ortopédica, cirugía abdominal, procedimientos neuroquirúrgicos, cirugía torácica.

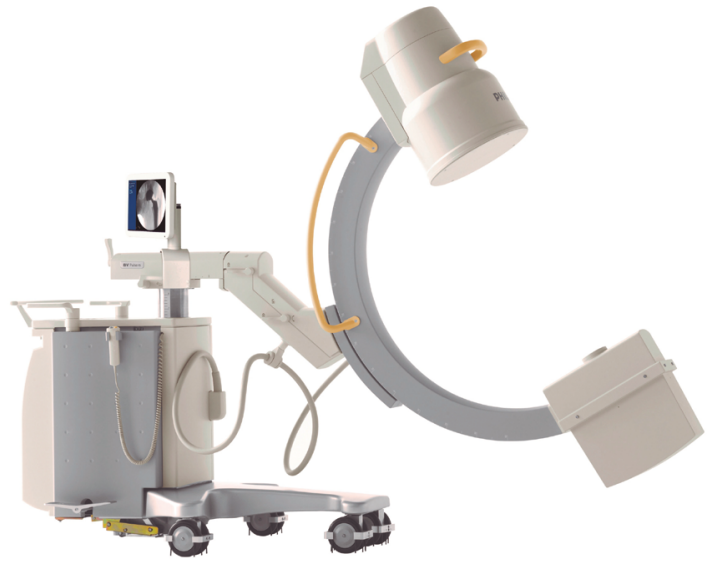

Figura 2. Arco en C Philips

Fuente https:/questimagingsolutions.com/news/2721/an-in-depth-lookinto-surgical-c-arms-what-to-buy-2/

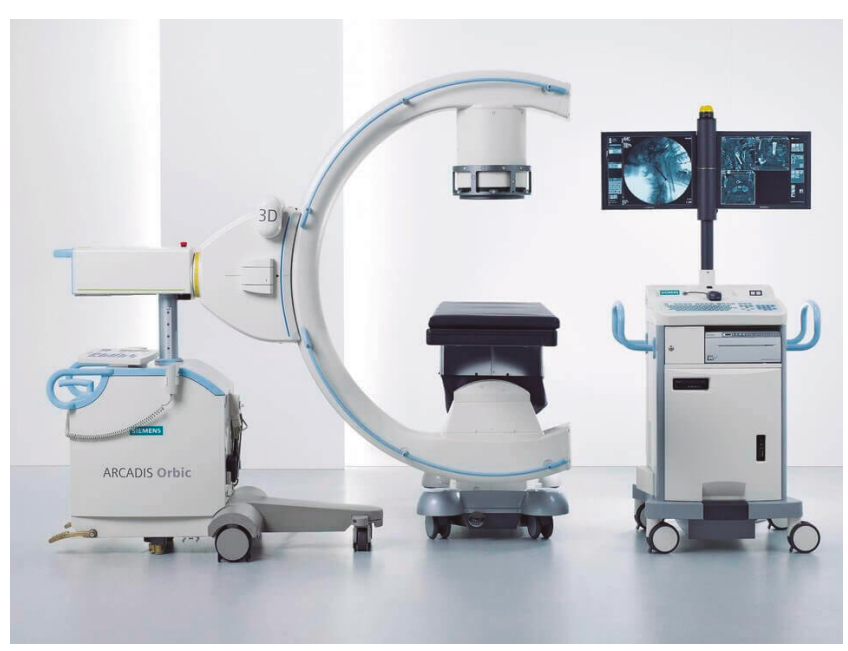

Figura 3. Arco en C Siemens

Fuente https://www.siemens-healthineers.com/es/surgical-c-arms-and-navigation/mobile-c-arms/arcadis-orbic-3d

\section{ANGIOGRAFÍA}

La angiografía es el estudio de los conductos sanguíneos (arterias, venas y capilares) por medio de la fluoroscopia y de la incorporación de medios de contraste, que por lo regular son líquidos que aumentan la densidad de la sangre temporalmente sin dejar efectos secundarios. Estos líquidos son inyectados justo en la zona que se desea estudiar, por medio de un catéter que, de igual manera, es incorporado vía intravenosa para ser observado en los monitores de TV.

Los sistemas de angiografía con sustracción digital (DSA) se usan en las aplicaciones vasculares y en la angiografía moderna. La figura 4a muestra una imagen sin substraer y 


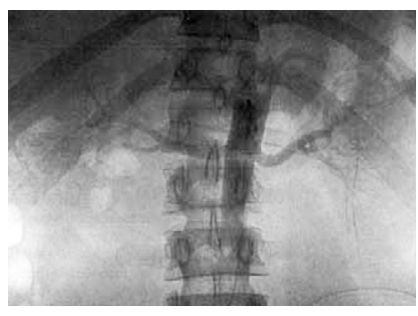

a. Columna lumbar

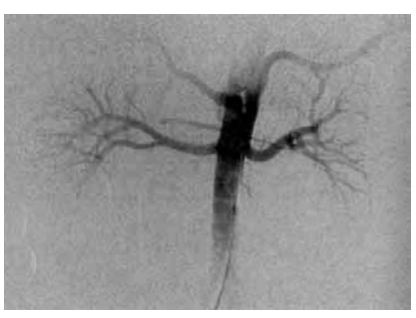

b. Sustracción
Figura 4. Angiografía con sustracción digital

la figura $4 \mathrm{~b}$, una imagen con sustracción. Se basa en la adquisición digital de imágenes antes y después de la inyección del medio de contraste en el sistema circulatorio. Las imágenes obtenidas sin contraste, también denominadas imágenes de máscara, son restadas píxel a píxel de las obtenidas con contraste para resaltar el cambio en la atenuación de los rayos $\mathrm{X}$ debido a la presencia del medio de contraste (solución con yodo) en la sangre [9].

En la angiografía se utilizan corrientes pequeñas y tiempos prolongados; por lo tanto, para mantener una calidad de imagen alta se utiliza fluoroscopia pulsada en lugar de continua. En las unidades de hemodinamia en las que se realizan exploraciones del árbol coronario del corazón es común utilizar tasas de fluoroscopia y adquisición alta para evitar la pérdida de resolución espacial por el movimiento del corazón. Por el contrario, en los equipos de radiología vascular no son tan críticas las tasas de adquisición, y sí el tamaño del receptor de imagen (intensificador o panel plano, en los equipos más modernos), ya que muchas de las exploraciones se realizan en la zona abdominal o en el tronco del paciente [9].

El equipo de angiografía mostrado en las figuras 5 y 6 consta de un arco en $\mathrm{C}$ suspendido del techo, que incorpora el tubo de rayos $\mathrm{X}$ y el sistema receptor de imagen. El brazo en $\mathrm{C}$ puede moverse en casi todas las direcciones para permitir la mayor cantidad posible de proyecciones del paciente. Consta de una mesa elevable, con un tablero plano, flotante y deslizante que permite el acceso fácil al paciente. También contiene monitores de TV que posibilitan al especialista seguir la imagen en tiempo real mientras realiza la exploración [9]. Es necesario someter estos equipos a un proceso de esterilización antes de usarlos, o adaptarles una cobertura plástica esterilizada.

Las especificaciones de los angiógrafos evaluados en los diferentes centros hospitalarios de Colombia se encuentran a continuación:

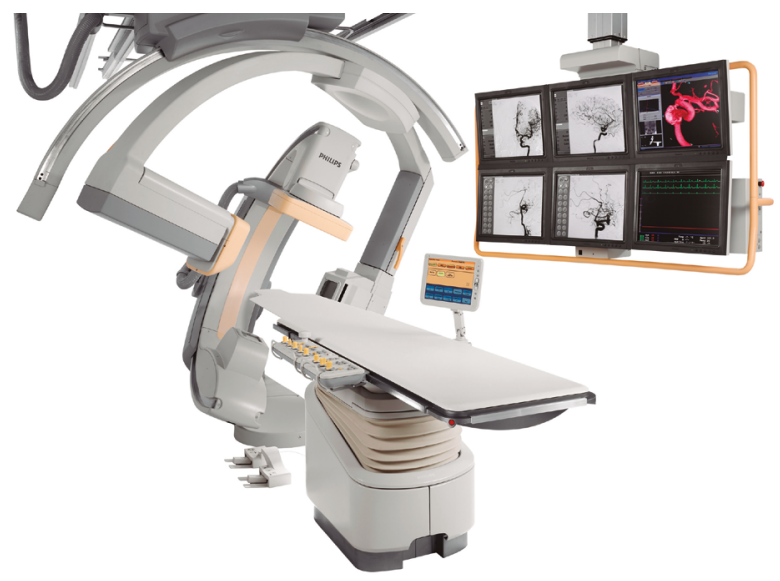

Figura 5. Angiógrafo Philips

Fuente: https://www.philips.com.co/healthcare/product/HC722029NE/ allura-xper-fd20-10-sistema-de-rayos-x-de-neuroradiologia-biplano

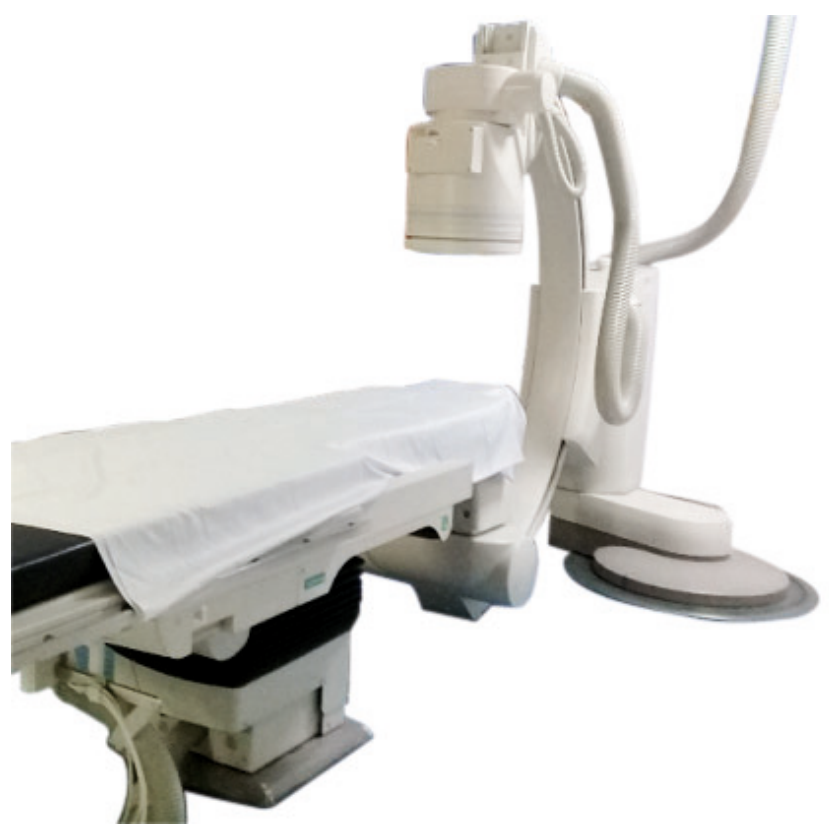

Figura 6. Angiógrafo Siemens

Tabla 4. Especificaciones del angiógrafo Philips

\begin{tabular}{lc}
\hline \multicolumn{1}{c}{ Servicio } & Radiodiagnóstico \\
\hline Modelo del equipo & Equipo \\
Serie del equipo & Allura XPER FD 20 \\
Marca del tubo & 222 \\
Serie del tubo & Philips \\
Fecha de fabricación & 22061 \\
\hline & 2016 \\
\hline Kilovoltaje máximo & Datos técnicos del equipo \\
Corriente máxima de tubo & $125 \mathrm{kVp}$ \\
Filtración agregada & $60 \mathrm{~mA}$ \\
Potencia del generador & $1,0 \mathrm{~mm}$ Al-70 kV \\
Potencia del tubo & $100 \mathrm{~kW}$ \\
Número de monitores & $32-68 \mathrm{~kW}$ \\
Modos de operación & 4 \\
\hline & Radio/fluoro \\
\hline
\end{tabular}

Los angiógrafos son utilizados en procedimientos de cardiología (arterias, corazón pediátrico), vascular (carótidas) y neurovascular. 
Tabla 5. Especificaciones del angiógrafo Siemens

\begin{tabular}{lc}
\hline \multicolumn{1}{c}{ Servicio } & Equipo \\
\hline Modelo del equipo & Axion Artis \\
N. ${ }^{0}$ del modelo del equipo & 5764522 \\
Serie del equipo & 777011692 \\
Marca del tubo & Siemenstico \\
N. ${ }^{0}$ del modelo del tubo & 3800351 \\
Serie del tubo & 975591506 \\
Fecha de fabricación & Marzo de 2012 \\
\hline & Datos técnicos del equipo \\
\hline Kilovoltaje máximo & $125 \mathrm{kVp}$ \\
Corriente máxima del tubo & $60 \mathrm{mAs}$ \\
Filtración agregada & $1,5 \mathrm{~mm}$ Al-75 kV \\
Número de monitores & 2 \\
Modos de operación & Radio/fluoro \\
\hline
\end{tabular}

Los angiógrafos son utilizados en procedimientos de cardiología (arterias, corazón pediátrico), vascular (carótidas) y neurovascular.

\section{DETECTORES, FANTOMAS Y HERRAMIENTAS}

Los instrumentos necesarios en la evaluación del comportamiento de los equipos fluoroscópicos se detallan a continuación:

\subsection{Detectores de radiación}

El Diavolt Universal PTW es un dispositivo diseñado para medir tiempo de exposición y tensión del tubo en equipos emisores de rayos $\mathrm{X}$ de uso clínico (radiografía, CT, fluoroscopia, mamografía). En el control de calidad de un equipo de an- giografía, el Diavolt se utiliza siempre con la aplicación RAD/ FLU. A la hora de medir la tensión, el dispositivo debe estar en el centro del campo de radiación para ser expuesto totalmente.

El detector semiconductor DiadosT60004 conectado a un electrómetro Diados E T11035 permite medir carga, dosis, tasa de dosis, pulso en aplicaciones radiológicas para equipos de rayos $\mathrm{X}$ en el rango de $40 \mathrm{a} 150 \mathrm{kV}$. En este trabajo, la magnitud de trazabilidad es el valor de carga; los valores de dosis o tasa de dosis se obtienen según el factor de corrección, dependiendo de la energía del haz $\left(N_{K}\right)$ y la posición del detector, junto con el factor de calibración del detector $\left(K_{Q}\right)$. En la cámara de ionización abierta se obtienen valores de dosis teniendo en cuenta la corrección por presión y temperatura $\left(K_{P T}\right)$.

\subsection{Construcción de fantomas}

Los fantomas mostrados en la figura 7 son elaborados en el Laboratorio de Radiaciones Nucleares de la UPTC. El fantoma adulto se construyó bajo las recomendaciones de la AAPM [10]. El fantoma pediátrico se elaboró teniendo en cuenta la medida promedio de la masa encefálica de un niño estándar (3 kg) y de un adulto $(6,5 \mathrm{~kg})$ [4]. De acuerdo con la relación entre las masas se estipula que el fantoma correspondiente al niño debe ser el $46 \%$ menos grande que el correspondiente al adulto.

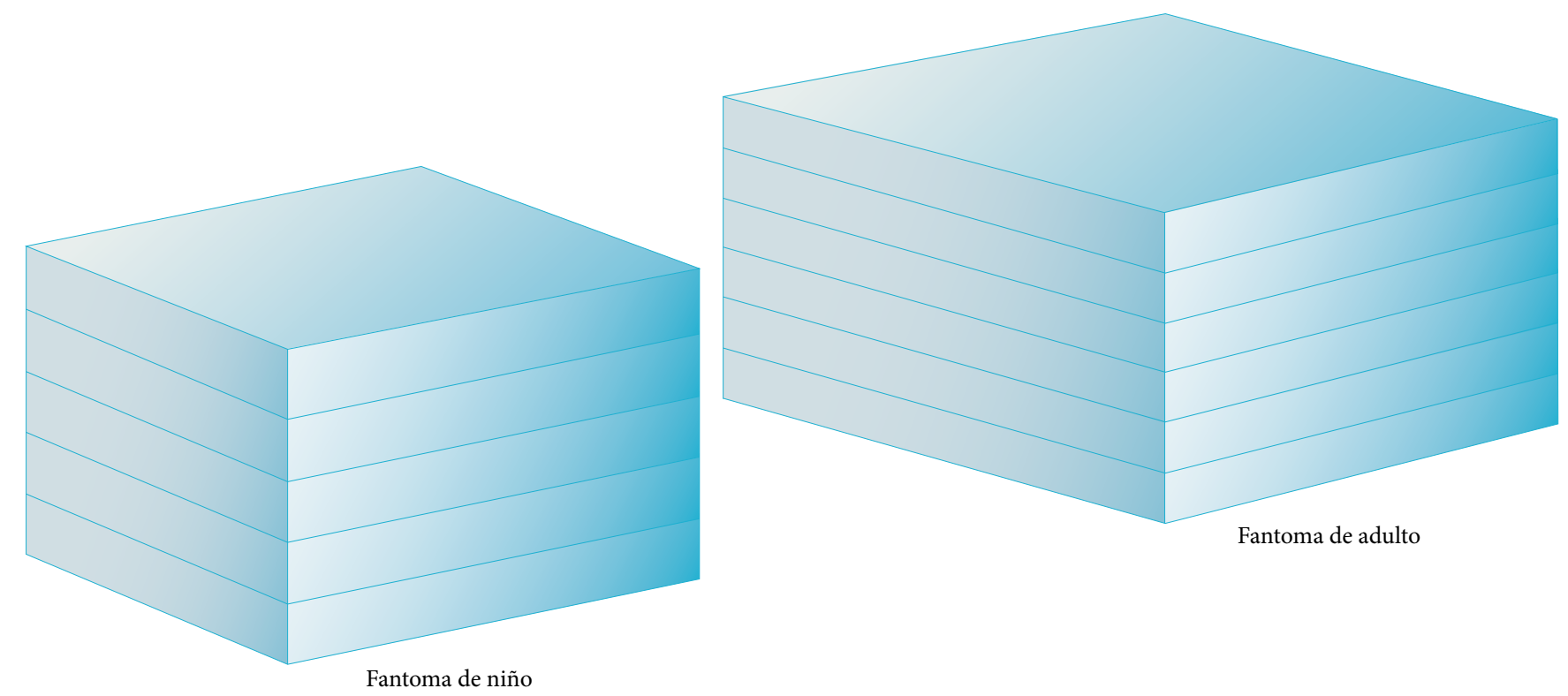

Figura 7. Fantomas 

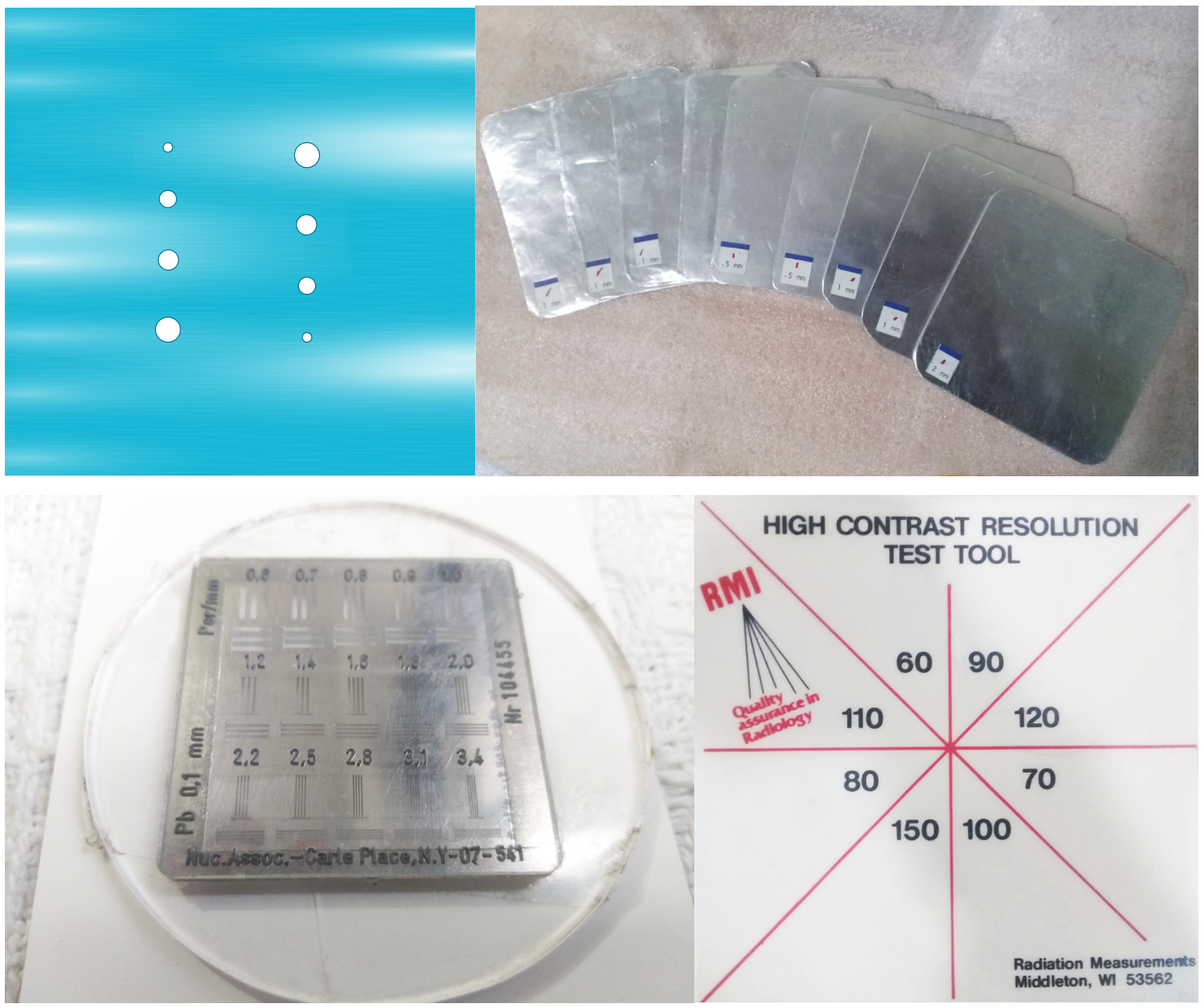

Figura 8. Herramientas

1. Lámina de aluminio con múltiples perforaciones elaborada para evaluar la resolución de bajo contraste en la imagen; 2 . Conjunto de filtros de aluminio utilizados para determinar la capa hemirreductora (CHR) del haz de rayos X; 3. Patrón de barras de plomo utilizado para estimar la resolución espacial en diferentes tamaños de campo de radiación, 4. Placa con mallas de cobre utilizada para evaluar la resolución de alto contraste en salas de cardiología.

\subsection{Herramientas}

En la figura 8 se muestran las herramientas recomendadas por los estándares nacionales e internacionales [11] para evaluar la calidad de la imagen en el monitor anclado al equipo emisor de rayos $\mathrm{X}$.

\section{METODOLOGÍA}

El desempeño de los equipos fluoroscópicos se evalúa mediante las pruebas de control de calidad. Estas son: coincidencia del campo de radiación con el detector, exactitud del valor nominal de la tensión del tubo de rayos $\mathrm{X}$, filtración del haz, compensación del control automático de exposición
(CAE) para distintos espesores, tasa de dosis a la entrada del paciente con $\mathrm{CAE}$, resolución espacial, resolución de bajo contraste y resolución de alto contraste de la imagen. A continuación se expone el protocolo detallado que se implementa en los equipos de angiografía, teniendo en cuenta los protocolos [2, 3] que recomienda la resolución 482 de $2018 \mathrm{del}$ Ministerio de Salud y Protección Social [1] para los equipos arco en $\mathrm{C}$ y telecomandado.

\subsection{Coincidencia del campo de radiación con el detector}

Tolerancias: La relación entre el área del campo de radiación $\left(A_{R X}\right)$ y el área de la superficie del detector $\left(A_{D}\right)$ no debe ser mayor a 1,15 . 
Material: Chasis cargado con película de rayos X.

Objetivo: Establecer las áreas reales del campo de radiación, con el fin de no irradiar partes innecesarias del cuerpo humano.

Procedimiento: Mantener el foco y el detector de imagen a una distancia de $120 \mathrm{~cm}$, con el colimador abierto al máximo. Ubicar un chasis cargado a la entrada del detector del angiógrafo. El tamaño del chasis debe ser mayor que la superficie del detector. A continuación se expone la película, y a partir de su revelado se miden los lados del cuadrado para calcular el área del campo de radiación. El valor nominal del campo a la entrada del detector es el ajustado por el equipo y se usa con el objetivo de calcular la relación entre el área del campo de radiación y el área de la superficie del detector.

\subsection{Exactitud del valor nominal de la tensión del tubo}

Tolerancias: Exactitud $< \pm 10 \%$

Material: Kilovoltímetro PTW Diavolt, 6 Placas de PMMA o acrílico (fantoma).

Objetivo: Obtener un estimativo real del kilovoltaje nominal para no sobredosificar las exposiciones al paciente.

Procedimiento: El kilovoltímetro y el atenuador deben ubicarse dentro del haz de rayos $\mathrm{X}$ del angiógrafo, de tal forma que no afecte el sistema de CAE.

Hay que interponer cuatro espesores diferentes con las placas de acrílico del fantoma para obtener cuatro valores distintos de tensión. Las placas deben encontrarse cerca al detector del angiógrafo, para la respectiva medición. Se deben registrar los valores de tensión y corriente que asigna el equipo de angiografía para cada placa del fantoma que se superpone en la camilla. Para cada kV hay que realizar de tres a cinco exposiciones, con un tiempo recomendado de $10 \mathrm{~s}$. Hay que registrar los valores de tensión obtenidos por el kilovoltímetro.

\subsection{Filtración del haz}

Tolerancias: Según especificaciones del fabricante.

Material: Detector semiconductor Diados T60004, electrómetro Diados E, placas de acrílico, conjunto de filtros de aluminio, placa de aluminio para proteger el detector $y$ cinta métrica.

Objetivo: Estimar la calidad del haz de radiación que se va a utilizar en los procedimientos intervencionistas de radiología.

Procedimiento: El angiógrafo no permite ajustar el voltaje de forma manual; por lo tanto, es necesario interponer siete placas de acrílico para obtener el valor de tensión deseado (70 $\mathrm{kV}$ ). Este material tiene una densidad similar a la del tejido blando del cuerpo humano, lo que permite que la perturbación del haz sea igual que cuando se tiene a una persona en la camilla del angiógrafo. Hay que ubicar las placas entre el detector Diados T60004 y el detector del equipo (II o panel plano) a una distancia de $10 \mathrm{~cm}$ entre el detector (II o panel plano) y el fantoma acorde con el angiógrafo. Debe cubrirse el detector del angiógrafo con una lámina de aluminio, para que no sufra daños. Hay que ubicar filtros de aluminio a la salida del colimador del tubo de rayos $\mathrm{X}$ y realizar entre tres y cinco exposiciones por cada lámina de aluminio (nueve filtros con espesores entre $0,1 \mathrm{~mm}$ y $2 \mathrm{~mm}$ ), con un tiempo recomendado de $10 \mathrm{~s}$ por exposición, y registrar los valores de dosis. Esto, con el fin de encontrar el espesor de aluminio, que permite que la intensidad de radiación se reduzca a la mitad (CHR).

\subsection{Compensación del CAE para distintos espesores \\ Tolerancia: $\leq \pm 20 \%$}

Material: Detector semiconductor Diados T60004, electrómetro Diados E, fantoma (seis placas de acrílico), cinta métrica.

Objetivo: Evaluar de manera automática la técnica radiológica expresada en potencial eléctrico y producto corriente-tiempo, reduciendo las dosis en pacientes.

Procedimiento: Hay que posicionar el detector semiconductor a la entrada del detector (II o panel plano) y las placas de acrílico de distintos espesores, entre 2,5 y $15 \mathrm{~cm}$. La distancia del tubo de rayos $\mathrm{X}$ al detector (II o panel plano) debe ser de $120 \mathrm{~cm}$. Hay que registrar la distancia del fantoma al Diados T60004. Para cada espesor de acrílico se deben usar los modos de operación más comunes. Hay que realizar de tres a cinco exposiciones y registrar los valores de tensión, corriente, filtración, tiempo y dosis. 


\subsection{Tasa de dosis a la entrada del paciente con CAE}

Tolerancias: Cuando la prueba se realiza con un fantoma de $20 \mathrm{~cm}$ de acrílico, estos deben ser los valores máximos de tasa de dosis: fluoroscopia en modo normal $\pm 50 \mathrm{mGy} / \mathrm{min}$, fluoroscopia de alta tasa de dosis $\pm 100 \mathrm{mGy} / \mathrm{min}$. En modo de adquisición no hay tolerancias.

Material: Fantoma (seis placas de acrílico), detector semiconductor Diados T60004, electrómetro Diados E, cinta métrica.

Objetivo: Verificar que las dosis en pacientes se encuentran por debajo de los niveles de referencia.

Procedimiento: Ubicar el Diados T60004 $1 \mathrm{~cm}$ por encima de la camilla del angiógrafo. Sobre el Diados T60004 deben interponerse espesores de acrílico de 2,5 a $15 \mathrm{~cm}$, de tal forma que no tengan contacto, para evitar daños en el detector semiconductor. Para la primera placa de $2,5 \mathrm{~cm}$ se realizan tres o cuatro exposiciones; para cada una se recomienda un tiempo de $10 \mathrm{~s}$. Hay que registrar los valores de tensión, corriente y tasa de dosis. A continuación, se coloca otra placa de acrílico y se registran los valores mencionados, y así sucesivamente hasta completar el fantoma de 15 $\mathrm{cm}$ de espesor.

\subsection{Resolución espacial}

Tolerancias: En los intensificadores de imagen con tamaño de campo de $36 \mathrm{~cm}$ se deben observar conjuntos de pares de líneas mayores o iguales a $0,9 \mathrm{pl} / \mathrm{mm}(\geq 0,9 \mathrm{pl} / \mathrm{mm})$; de 30 $\mathrm{cm} \geq 1,12 \mathrm{pl} / \mathrm{mm}$; de $23 \mathrm{~cm} \geq 1,2 \mathrm{pl} / \mathrm{mm}$; de $15 \mathrm{~cm}$ o inferiores $\geq 1,6 \mathrm{pl} / \mathrm{mm}$. En los paneles planos, según especificaciones del fabricante dado en unidades de $\mathrm{pl} / \mathrm{mm}$.

Material: Fantoma (seis placas de acrílico), cinta métrica, patrón de barras de plomo con espesor de $0,1 \mathrm{~mm}$, con diferentes grupos de líneas, y resoluciones entre $0,2 \mathrm{pl} / \mathrm{mm}$ y $3,4 \mathrm{pl} / \mathrm{mm}$.

Objetivo: Verificar el tamaño de punto focal reportado por el fabricante.

Procedimiento: Se coloca el patrón de barras en tres posiciones - debajo del fantoma, a la mitad del fantoma y a la entrada del detector del angiógrafo sin fantoma-, a una distancia foco-detector de $120 \mathrm{~cm}$. Se realiza una exposición en modo normal de operación en cada posición del patrón y se identifica hasta qué conjunto de pares de líneas es visible en la imagen.

\subsection{Resolución de bajo contraste}

Tolerancias: En la imagen almacenada en el monitor de TV se deben identificar todos los agujeros de la herramienta de prueba.

Material: Fantoma (seis placas de acrílico), cinta métrica, lámina de aluminio de $1 \mathrm{~mm}$ de espesor, multiperforada (objeto de prueba).

Objetivo: Reportar el funcionamiento del equipo mediante la identificación de detalles en la imagen sobre la herramienta de prueba.

Procedimiento: Se ubica la lámina de aluminio en las mismas posiciones mencionadas en la prueba de resolución espacial, a una distancia foco-detector de $120 \mathrm{~cm}$. De igual forma, se realiza una exposición en modo normal de operación por cada posición del patrón y se identifica qué agujeros son visibles en la imagen.

\subsection{Resolución de alto contraste}

Tolerancias: En detectores de panel plano se deben visualizar las mallas de 80 a 110 agujeros por pulgada. En los intensificadores de imagen se deben visualizar las mallas de 70 a 90 agujeros por pulgada.

Material: Patrón de cobre perforado, fantoma (seis placas de acrílico), cinta métrica.

Objetivo: Reportar el funcionamiento del equipo mediante la identificación de detalles en la imagen sobre la herramienta de prueba.

Procedimiento: Se ubica la lámina a la entrada del detector, a una distancia foco-detector de $120 \mathrm{~cm}$. Se realiza una exposición en modo normal de operación. Se identificar el tipo de malla de cobre que se observa en la imagen sobre el monitor. 


\section{RESULTADOS}

\subsection{Coincidencia del campo de radiación con el detector}

En la figura 9 se muestra la imagen almacenada del campo de radiación por el angiógrafo Philips y el equipo telecomandado.

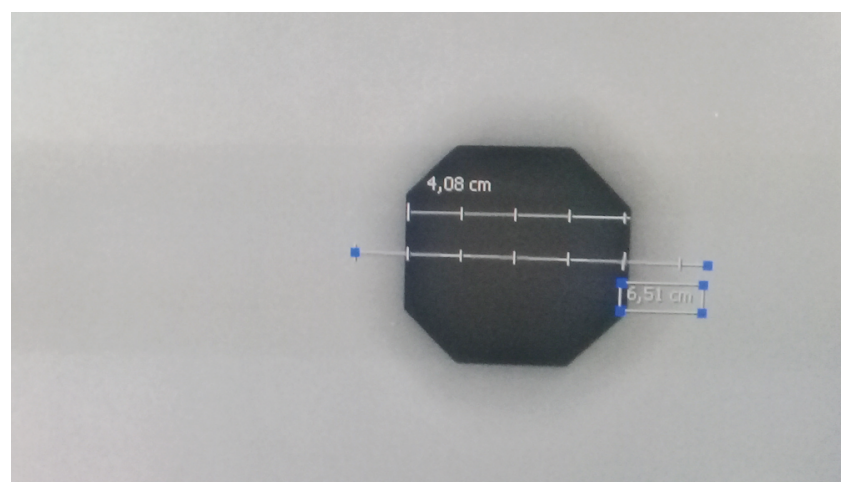

Angiógrafo Phillips

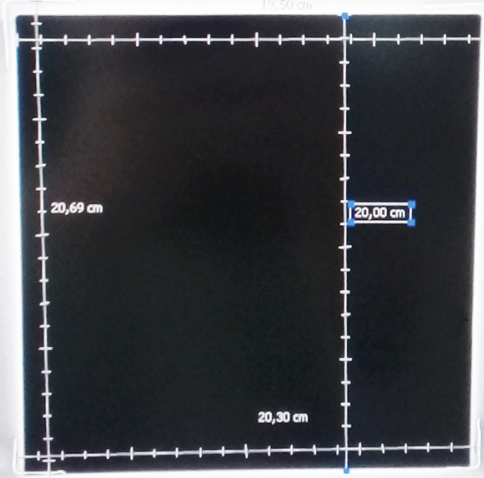

Telecomando

Figura 9. Imagen del campo de radiación en el angiógrafo Philips y el equipo telecomandado

Las medidas en la imagen corresponden a la longitud de los lados del campo de radiación. En la tabla 6 se exponen las dimensiones del campo luminoso y de radiación.

El error que se registra en el equipo telecomandado de 0,1 indica la penumbra que existe entre el campo luminoso y el tamaño de campo seleccionado en la colimación del haz. La tolerancia permitida en la coincidencia del campo de radiación con el detector del equipo emisor de rayos $\mathrm{X}$ debe ser menor de $1,15\left(\frac{A_{R X}}{A_{D}}<1,15\right)$. Por lo tanto, se cumple.

Tabla 6. Relación del campo de radiación con el detector correspondiente al angiógrafo Philips y el equipo telecomandado

\begin{tabular}{cccc}
\hline Equipo & C. de radiación & C. detector & $\boldsymbol{A}_{R X} / \boldsymbol{A}_{D}$ \\
\hline Angiógrafo Philips & $4,08 \mathrm{~cm} \mathrm{x} \mathrm{4,08cm}$ & $4 \mathrm{~cm} \mathrm{\times} 4 \mathrm{~cm}$ & 1,04 \\
\hline $\begin{array}{c}\text { Equipo } \\
\text { telecomandado }\end{array}$ & $\begin{array}{c}19,50 \mathrm{~cm} \mathrm{x} 20,00 \\
\mathrm{~cm}\end{array}$ & $20 \mathrm{~cm} \mathrm{\times} 20 \mathrm{~cm}$ & $0,975 \pm 0,1$ \\
\hline
\end{tabular}

\subsection{Exactitud del valor nominal de la tensión del tubo}

Tabla 7. Desviación máxima del valor nominal de la tensión del tubo en el angiógrafo Philips

\begin{tabular}{ccc}
\hline \multicolumn{3}{c}{ Producto $(\mathbf{m A s})=\mathbf{2 5}$; DFD $=\mathbf{1 2 0} \mathbf{~ c m}$; DFS Diavolt $=\mathbf{6 0} \mathbf{~ c m}$; tiempo de exp. $=\mathbf{5} \pm \mathbf{0 , 1} \mathbf{~ s}$} \\
\hline Kilovoltaje nominal $(\mathbf{k V})$ & Kilovoltaje medido $(\mathbf{k V})$ & Desviación máxima \\
\hline 58,7 & $59,2 \pm 0,5$ & $0,85 \%$ \\
\hline 65,4 & $66,4 \pm 0,5$ & $1,53 \%$ \\
\hline 72,6 & $73,1 \pm 0,6$ & $0,69 \%$ \\
\hline 85,0 & $86,2 \pm 0,5$ & $1,41 \%$ \\
\hline
\end{tabular}

Tabla 8. Desviación máxima del valor nominal de la tensión del tubo en el angiógrafo Siemens

\begin{tabular}{ccc}
\hline \multicolumn{2}{c}{ Producto $(\mathbf{m A s}) \mathbf{=} \mathbf{2 0} ; \mathbf{D F D} \mathbf{=} \mathbf{1 2 0} \mathbf{~ c m}$; $\mathbf{D F S}$ Diavolt $=\mathbf{6 0} \mathbf{~ c m}$; tiempo de exp. $=\mathbf{5} \pm \mathbf{0 , \mathbf { 1 ~ s }}$} \\
\hline Kilovoltaje nominal $(\mathbf{k V})$ & Kilovoltaje medido $(\mathbf{k V})$ & Desviación máxima \\
\hline 65,7 & $64,3 \pm 0,5$ & $2,13 \%$ \\
\hline 77,2 & $75,1 \pm 0,4$ & $2,72 \%$ \\
\hline 86,4 & $88,9 \pm 0,3$ & $2,89 \%$ \\
\hline 98,2 & $100,6 \pm 0,4$ & $2,44 \%$ \\
\hline
\end{tabular}

Tabla 9. Desviación máxima del valor nominal de la tensión del tubo para el arco en C Philips

\begin{tabular}{|c|c|c|}
\hline \multicolumn{3}{|c|}{ Producto $(\mathrm{mAs})=30 ;$ DFD $=100 \mathrm{~cm} ;$ DFS Diavolt $=90 \mathrm{~cm} ;$ tiempo de exp. $=5 \pm 0,1 \mathrm{~s}$} \\
\hline Kilovoltaje nominal (kV) & Kilovoltaje medido (kV) & Desviación máxima \\
\hline 56,5 & $57,01 \pm 0,4$ & $0,9 \%$ \\
\hline 66,2 & $66,85 \pm 0,5$ & $1,0 \%$ \\
\hline 74,4 & $75,43 \pm 0,4$ & $1,4 \%$ \\
\hline 88,5 & $89,28 \pm 0,5$ & $0,9 \%$ \\
\hline
\end{tabular}

Tabla 10. Desviación máxima del valor nominal de la tensión del tubo en el arco en C Siemens

\begin{tabular}{ccc}
\hline \multicolumn{2}{c}{ Producto $(\mathbf{m A s})=\mathbf{3 0}$; DFD $=\mathbf{1 0 0} \mathbf{~ c m}$; DFS Diavolt $=\mathbf{9 0} \mathbf{~ c m}$; tiempo de exp. $=\mathbf{5} \pm \mathbf{0 , 1} \mathbf{~}$} \\
\hline Kilovoltaje nominal $(\mathrm{kV})$ & Kilovoltaje medido $(\mathrm{kV})$ & Desviación máxima \\
\hline 55,22 & $56,19 \pm 0,6$ & $1,76 \%$ \\
\hline 64,17 & $64,17 \pm 0,6$ & $1,51 \%$ \\
\hline 72,15 & $72,15 \pm 0,7$ & $1,34 \%$ \\
\hline 81,14 & $81,14 \pm 0,5$ & $2,01 \%$ \\
\hline
\end{tabular}

Se puede observar que la desviación máxima entre los valores de tensión nominales y medidos en los angiógrafos $\mathrm{y}$ arcos en $\mathrm{C}$ fue del 2,89\%. Este valor se encuentra en el rango de la tolerancia permitida $(<10 \%)$ en esta prueba. Los valores de tensión ajustados por el arco en $\mathrm{C}$ Siemens son mayores que los de los otros equipos evaluados.

\subsection{Filtración del haz}

En la gráfica de la figura 10 se observa que la intensidad de radiación disminuye de forma exponencial a medida que aumenta la filtración de aluminio. A partir del ajuste exponencial de los datos, encontramos que el espesor del filtro de aluminio que reduce la dosis de radiación a la mitad (CHR) es de $0,98 \mathrm{~mm}$. De acuerdo con las especificaciones del fabricante, la filtración total del angiógrafo marca Philips debe ser de $1 \mathrm{~mm} \mathrm{Al} \mathrm{a} 70 \mathrm{kV}$, lo que permite demostrar que el equipo se encuentra funcionando correctamente. 
En la gráfica de la figura 11 se encuentra la intensidad de radiación en función del filtro de aluminio correspondiente a diferentes valores de tensión.

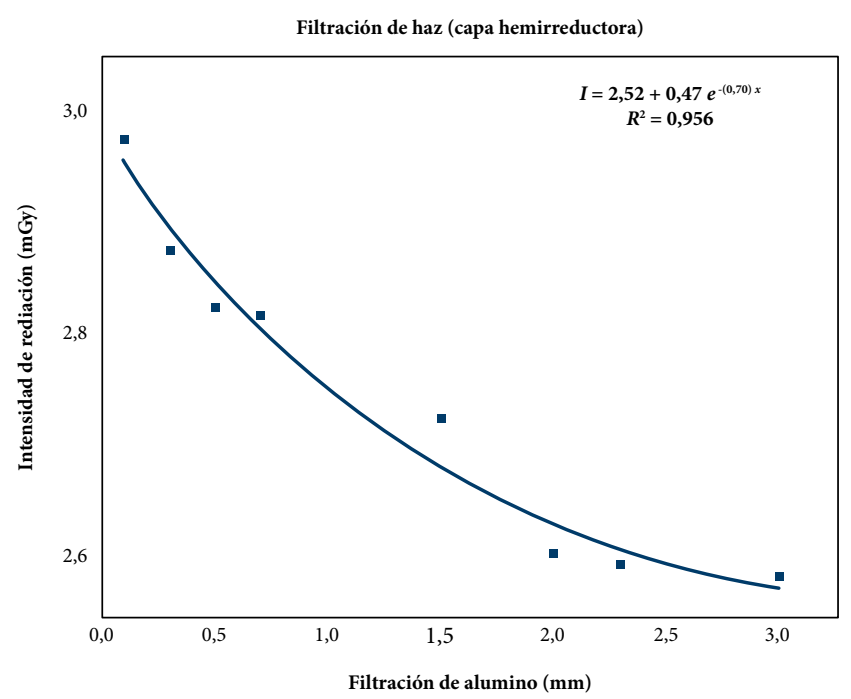

Figura 10. Capa hemirreductora de radiación correspondiente al angiógrafo Philips

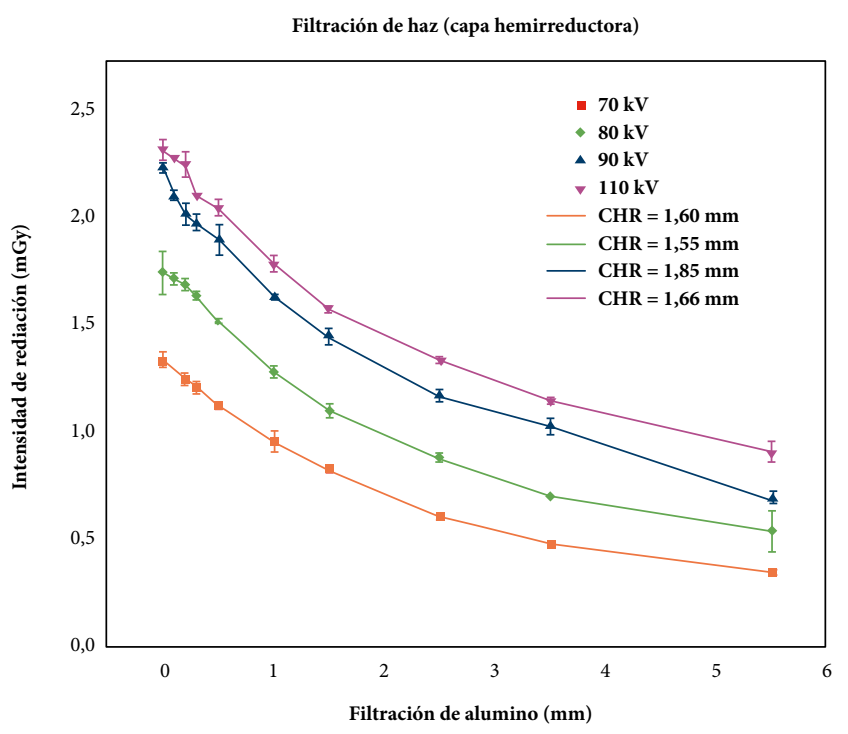

Figura 11. Capa hemirreductora de radiación en el equipo telecomandado

En el equipo telecomandado, según las especificaciones del fabricante, la filtración mínima es de 1,2 $\mathrm{mm} \mathrm{Al} \mathrm{a}$ $70 \mathrm{kV}$, y la filtración total es de $2,5 \mathrm{~mm} \mathrm{Al} \mathrm{a} 70 \mathrm{kV}$. En el ajuste exponencial de los datos obtenidos para este valor de tensión se determina que la capa hemirreductora es de 1,60 $\mathrm{mm} \mathrm{Al}$. Por lo tanto, se puede concluir que la capa hemirreductora se encuentra dentro de los límites de aceptabilidad.

\subsection{Compensación del CAE para distintos espesores}

Las dosis absorbidas a la entrada del detector de los angiógrafos Philips y Siemens, dependiendo del espesor del acrílico interpuesto entre el tubo y el detector, se encuentran a continuación:

Tabla 11. Dosis absorbidas a la entrada del detector del angiógrafo Philips

\begin{tabular}{|c|c|c|c|c|}
\hline \multicolumn{5}{|c|}{$\begin{aligned} \text { DFD = } 120 \mathrm{~cm} ; \text { DFS cámara de ionización }=119 \mathrm{~cm} ; \text { tiempo de exp. } \\
$\[ =30 \pm 0,2 \mathrm{~s} ; K_{P T}=1,342 \]$\end{aligned}$} \\
\hline $\begin{array}{c}\text { Espesor } \\
(\mathrm{cm})\end{array}$ & $\begin{array}{c}\text { Tensión } \\
(\mathrm{kV})\end{array}$ & $\begin{array}{c}\text { Corriente } \\
(\mathrm{mA})\end{array}$ & $\begin{array}{l}\text { Dosis } \\
\text { (mGy) }\end{array}$ & $\begin{array}{l}\text { Desvia. } \\
\text { Max. }\end{array}$ \\
\hline 0 & 57,5 & 35,3 & $0,23 \pm 0,04$ & $8,3 \%$ \\
\hline 2,5 & 58,0 & 40,4 & $0,41 \pm 0,04$ & $7,1 \%$ \\
\hline 5 & 60,3 & 45,5 & $0,57 \pm 0,05$ & $11,1 \%$ \\
\hline 7,5 & 61,8 & 45,5 & $0,71 \pm 0,04$ & $3,0 \%$ \\
\hline 10 & 67,2 & 52,5 & $0,90 \pm 0,05$ & $6,0 \%$ \\
\hline 12,5 & 69,0 & 53,4 & $1,10 \pm 0,06$ & $5,3 \%$ \\
\hline 15 & 70,4 & 56,4 & $1,35 \pm 0,06$ & $8,5 \%$ \\
\hline 17,5 & 71,2 & 57,2 & $1,82 \pm 0,05$ & $7,0 \%$ \\
\hline
\end{tabular}

Tabla 12. Dosis absorbidas a la entrada del detector del angiógrafo Siemens

\begin{tabular}{|c|c|c|c|c|}
\hline \multicolumn{5}{|c|}{ 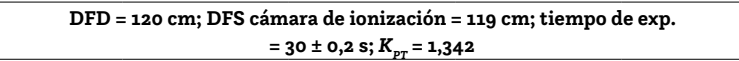 } \\
\hline $\begin{array}{c}\text { Espesor } \\
(\mathrm{cm})\end{array}$ & $\begin{array}{c}\text { Tensión } \\
(\mathrm{kV})\end{array}$ & $\begin{array}{c}\text { Corriente } \\
(\mathrm{mA})\end{array}$ & $\begin{array}{l}\text { Dosis } \\
\text { (mGy) }\end{array}$ & $\begin{array}{l}\text { Desvia. } \\
\text { Max. }\end{array}$ \\
\hline 0 & 58,0 & 87,0 & $0,11 \pm 0,05$ & $7,1 \%$ \\
\hline 2,5 & 58,0 & 121,0 & $0,21 \pm 0,06$ & $6,2 \%$ \\
\hline 5 & 59,2 & 156,8 & $0,29 \pm 0,06$ & $11,3 \%$ \\
\hline 7,5 & 61,2 & 169,8 & $0,44 \pm 0,06$ & $4,5 \%$ \\
\hline 10 & 66,0 & 85,0 & $0,62 \pm 0,05$ & $6,4 \%$ \\
\hline 12,5 & 66,0 & 119,4 & $1,03 \pm 0,06$ & $9,4 \%$ \\
\hline 15 & 68,2 & 159,5 & $1,37 \pm 0,07$ & $6,5 \%$ \\
\hline 17,5 & 68,8 & 164,5 & $1,92 \pm 0,06$ & $8,7 \%$ \\
\hline
\end{tabular}

La desviación máxima encontrada de los valores obtenidos de dosis absorbidas, tras comparar ambos angiógrafos, fue de $11,3 \%$. Este valor se encuentra dentro de la tolerancia aceptada de $\leq \pm 20 \%$ para los equipos emisores de rayos $\mathrm{X}$ fluoroscópicos.

\subsection{Tasa de dosis a la entrada del paciente con CAE}

Las tasas de dosis a la entrada del paciente fueron medidas de la siguiente manera:

En el angiógrafo Philips, en el equipo telecomandado y en los arcos en C, el dispositivo de medida fue el detector Diados T6004 a la entrada del fantoma. Los valores de tasa de dosis se obtienen a partir del valor de carga que arroja el electrómetro Diados E, multiplicado por un factor de corrección de acuerdo con la calidad del haz y un factor de calibración del dispositivo, divido por el tiempo de exposición de la radiación.

En el angiógrafo Siemens, el dispositivo de medida fue la cámara de ionización abierta. Los valores de tasa de dosis se obtienen a partir del valor de dosis absorbida arrojado por la cámara, que se divide por el tiempo de exposición a la radiación. 


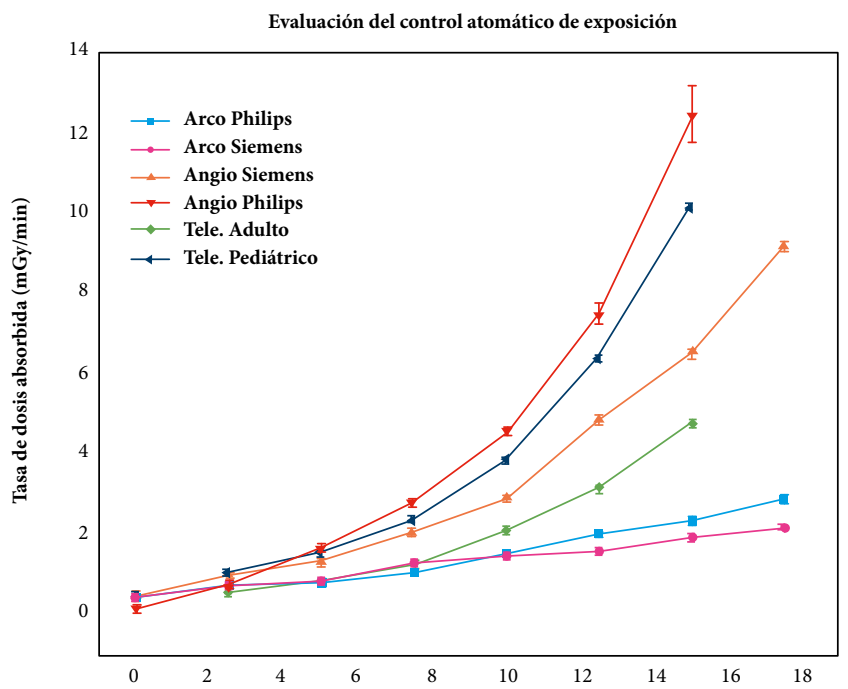

Figura 12. Evaluación del control automático de exposición de todos los equipos

En la gráfica de la figura 12 se puede observar que a medida que aumenta el espesor del acrílico, la tasa de dosis absorbida aumenta de forma exponencial. Este comportamiento se replica cuando se tiene a un paciente interpuesto entre el tubo de rayos $\mathrm{X}$ y el detector del equipo, ya que si es de contextura gruesa, se requerirá de altas tasas de dosis para obtener buena calidad de imagen. Si se hace una comparación entre equipos, se puede notar en la gráfica que las tasas de dosis son mayores en los equipos de marca Philips.

En el equipo telecomandado, cuando se usa el fantoma correspondiente a niños, las tasas de dosis son mayores que
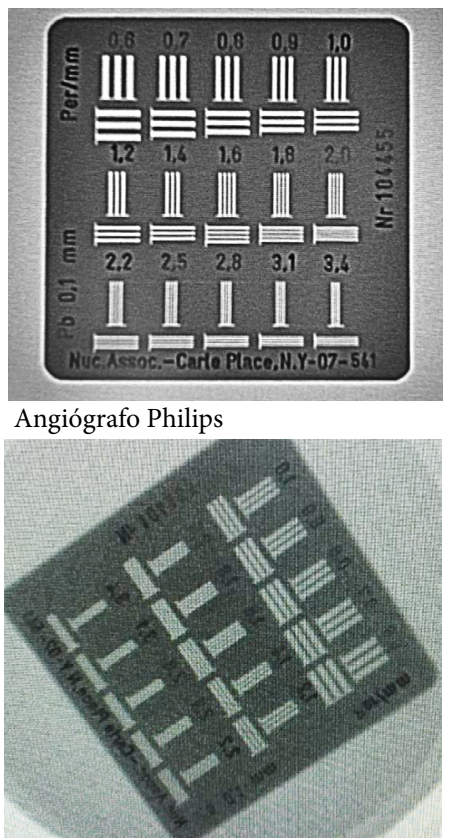

Arco en C Siemens

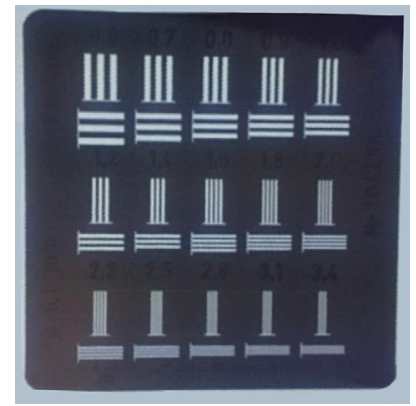

Angiógrafo Siemens

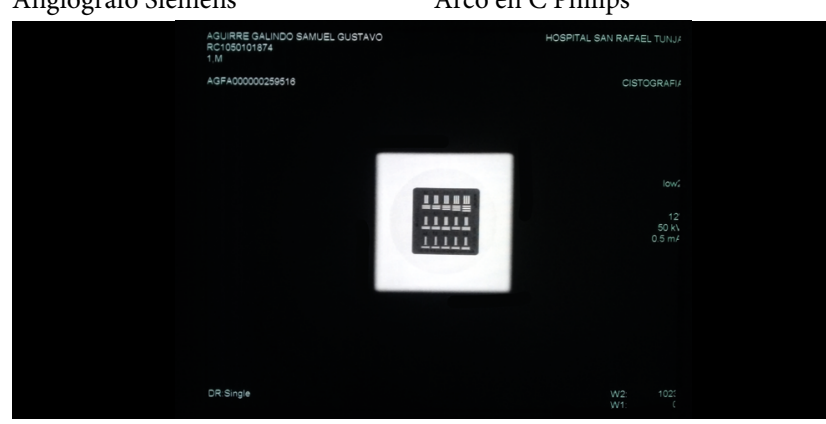

Telecomando

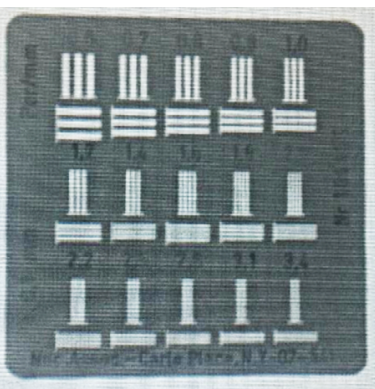

Arco en C Philips

las que se registran con el fantoma de adulto. Esto se debe a que el tamaño de campo es menor.

Si se comparan los angiógrafos, la tasa de dosis máxima en distintos espesores fue de 13,20 \pm 0,24 $\mathrm{mGy} / \mathrm{min}$ para un espesor de $15 \mathrm{~cm}$ de acrílico y un tiempo de exposición de 10 $s$, a lo que corresponde un valor aceptable en el rango de la tolerancia permitida $(50 \mathrm{mGy} / \mathrm{min}$ para un espesor de acrílico de $20 \mathrm{~cm}$ ). La tasa de dosis máxima en distintos espesores, comparando los arcos en $\mathrm{C}$, fue de 2,90 \pm 0,08 $\mathrm{mGy} / \mathrm{min}$ para un espesor de 17,5 cm de acrílico, y un tiempo de exposición de $30 \mathrm{~s}$, y corresponde a una pequeña tasa de dosis, si se compara con la tolerancia permitida, debido al tiempo de exposición, que fue mayor que el usado con los angiógrafos.

La tasa de dosis máxima para distintos espesores de acrílico del fantoma de adulto en el equipo telecomandado fue de 4,80 \pm 0,12 $\mathrm{mGy} / \mathrm{min}$, para un tamaño de campo de $25 \times$ $25 \mathrm{~cm}$, y con el fantoma de niño fue de 10,20 \pm 0,08 mGy/ min para un tamaño de campo de $17 \times 17 \mathrm{~cm}$, con un tiempo de exposición de $15 \mathrm{~s}$. El valor corresponde a una tasa de dosis pequeña debido a que el tiempo de exposición es mayor y existen variaciones en la colimación del haz.

\subsection{Resolución espacial}

Las imágenes almacenadas por los cinco equipos emisores de rayos $\mathrm{X}$ del patrón de barras de plomo se muestran en la figura 13. El tamaño de campo de los angiógrafos y el equipo telecomandado fue de $10 \times 10 \mathrm{~cm}$, y en los arcos en $\mathrm{C}$, de $17 \times 17 \mathrm{~cm}$.

Figura 13. Imágenes del patrón de barras en cada uno de los equipos 
Las imágenes obtenidas fueron evaluadas sobre la pantalla del monitor de TV, donde se pudo observar que en los angiógrafos, el conjunto de pares de líneas más pequeño que se puede resolver fue de $1,6 \mathrm{pl} / \mathrm{mm}$; en el arco en C Philips fue de 1,4 $\mathrm{pl} / \mathrm{mm}$; en el arco en C Siemens, de $1,2 \mathrm{pl} / \mathrm{mm}$, y en el equipo telecomandado no fue posible identificar las barras de la herramienta debido a una complicación en el software para acercar la imagen. Las variaciones son mínimas en los parámetros eléctricos que ajustan los equipos con el patrón de barras interpuesto entre el tubo de rayos $\mathrm{X}$ y el detector (II o panel plano).

Los conjuntos de pares de líneas observados se encuentran dentro de los márgenes de aceptabilidad, ya que, para tamaños de campo $\leq 15 \mathrm{~cm}$ se deben identificar conjuntos $\geq 1,6 \mathrm{pl} / \mathrm{mm}$, y para tamaños de campo menores de $23 \mathrm{~cm}$ y mayores de $15 \mathrm{~cm}$ los conjuntos que deben identificarse deben ser $\geq 1,2 \mathrm{pl} / \mathrm{mm}$.

\subsection{Resolución de bajo contraste}

Las imágenes almacenadas por los cinco equipos emisores de rayos $\mathrm{X}$ de la lámina de aluminio con múltiples perforaciones se muestra en la figura 14.

Las imágenes obtenidas fueron evaluadas sobre la pantalla del monitor de TV, donde se pudo observar que todos los agujeros de la herramienta de prueba fueron identificados; por lo tanto, se determinó que los equipos funcionan correctamente. En el angiógrafo Philips, la resolución de bajo contraste se evalúo en los dos casos en que la herramienta se ubica sobre la camilla sin fantoma y con fantoma. En las imágenes almacenadas por el equipo se identificaron los agujeros con la diferencia de que con fantoma se aprecia ruido, debido a que el detector recibe mayor cantidad de fotones $\mathrm{X}$.

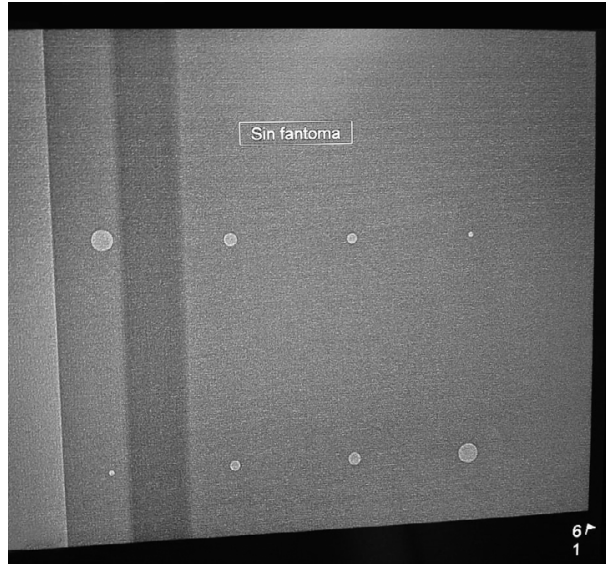

Angiógrafo Philips

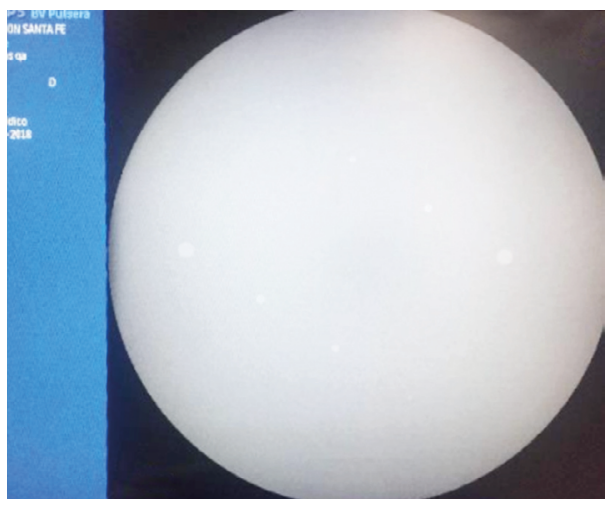

Arco en C Philips

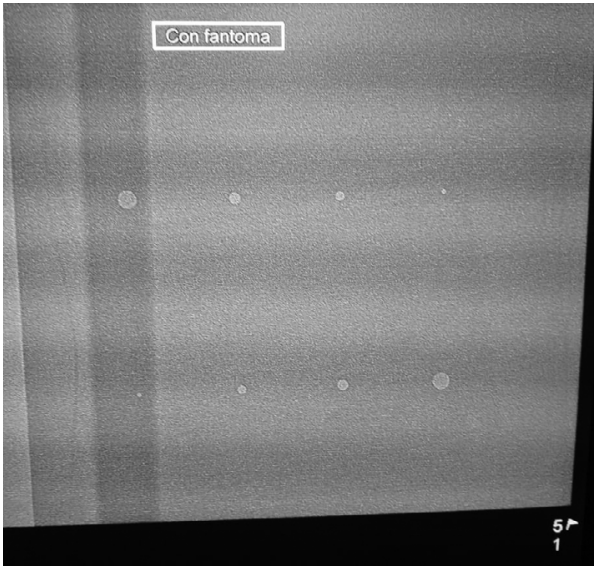

Angiógrafo Philips

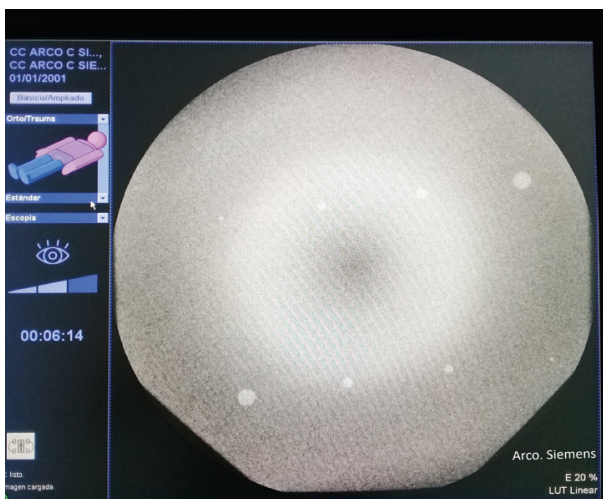

Arco en C Siemens

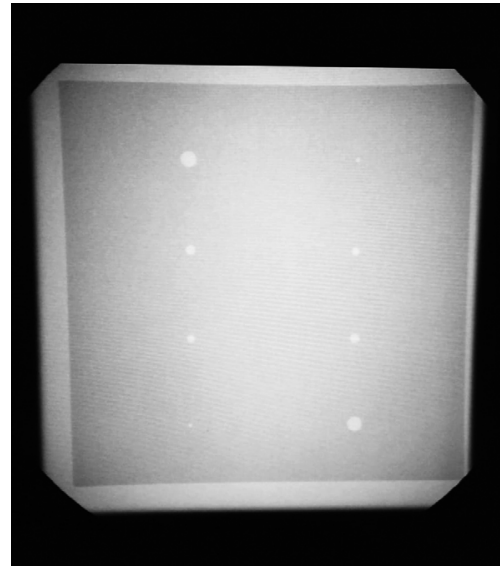

Angiógrafo Siemens

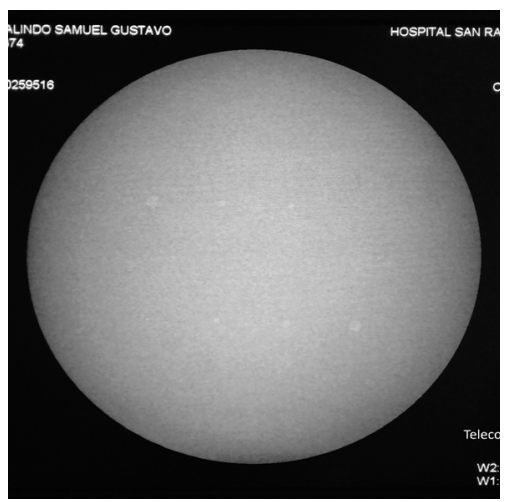

Telecomando

Figura 14. Imágenes de la lámina de aluminio correspondiente a cada uno de los equipos fluoroscópicos 


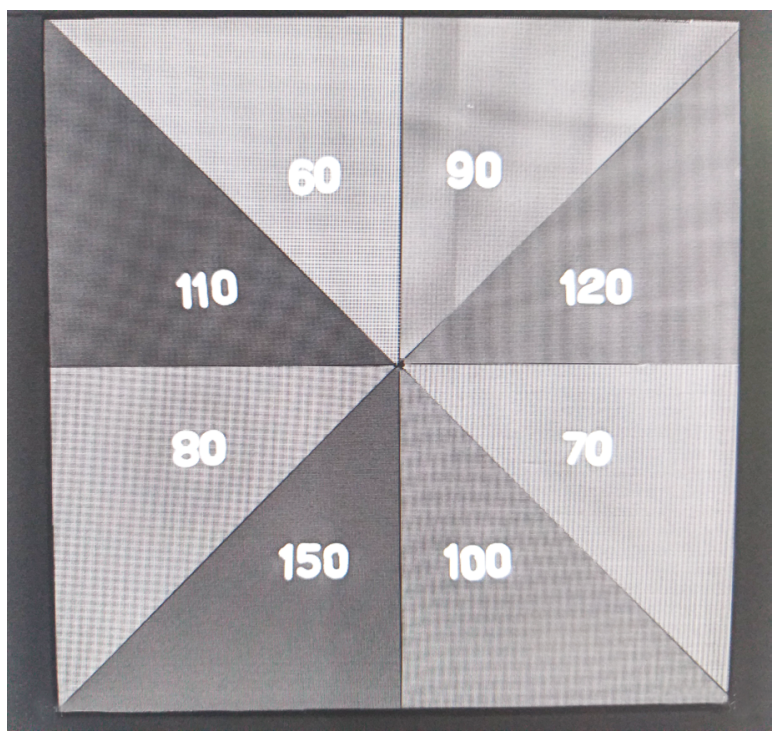

Angiógrafo Philips

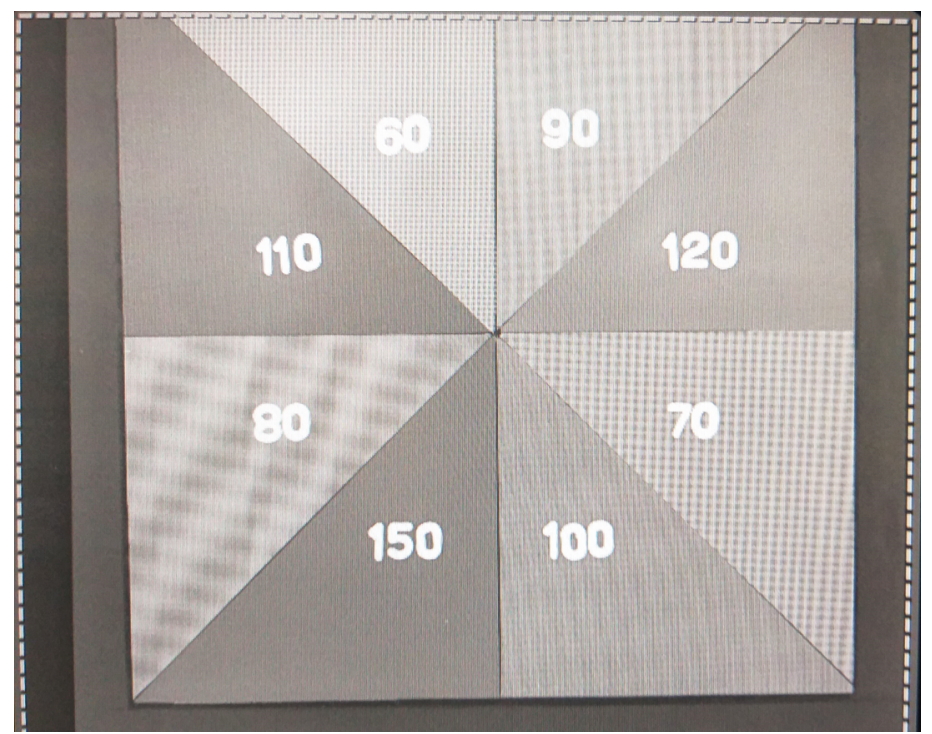

Telecomando

Figura 15. Imagen de la placa con mallas de cobre en el angiógrafo Philips y el equipo telecomandado

\subsection{Resolución de alto contraste}

Esta prueba se realizó en el equipo telecomandado y el angiógrafo Phillips. Las imágenes se muestran en la figura 15.

Las imágenes obtenidas fueron evaluadas sobre la pantalla del monitor de TV, donde se pudo observar que los números de malla visibles en la imagen almacenada por el angiógrafo Philips son los de 80 y 100 agujeros por pulgada. En el equipo telecomandado los números de malla visibles son los de 70 y 90 agujeros por pulgada. Por consiguiente, se puede concluir que las mallas visualizadas en la imagen se encuentran dentro de los márgenes de aceptabilidad, ya que para los intensificadores de imagen las mallas que se deben resolver en la imagen van de 70 a 90 agujeros por pulgada, y en los detectores de panel plano van de 80 a 110 agujeros por pulgada.

\section{CONCLUSIONES}

1. Los equipos evaluados en los diferentes centros hospitalarios de Colombia cumplieron con los estándares de control de calidad exigidos en la Resolución 482 de 2018 del Ministerio de Salud y Protección Social [1], ya que las pruebas evaluadas en cuanto a parámetros geométricos, calidad del haz, dosis al paciente y calidad de imagen según las recomendaciones de los protocolos se encontraron dentro de los márgenes de aceptabilidad.

2. Se identificó que en el equipo telecomandado no se cumplieron las tolerancias permitidas en la prueba de resolución espacial; por lo tanto, se informó en el servicio de especialidades médicas del hospital correspondiente que se deben hacer las correcciones pertinentes.

3. El prototipo de fantoma para angiografía cerebral construido permitió la completa realización de las pruebas que constituyen los protocolos de control de calidad.

4. Se observó que los parámetros medidos en las pruebas de control de calidad varían de forma significativa, dependiendo del fabricante del equipo. Haciendo una comparación entre equipos de angiografía y arcos en C se observa que el fabricante Philips arroja mayor cantidad de tasas de dosis. Cuando se tienen un espesor de $15 \mathrm{~cm}$ de acrílico y un tiempo de exposición de $10 \mathrm{~s}$, el angiógrafo Philips brinda una mayor tasa de dosis (de $13,20 \pm 0,24 \mathrm{mGy} / \mathrm{min}$ ), con una energía de $80 \mathrm{kV}$ y un producto de corriente-tiempo de $16 \mathrm{mAs}$.

5. Este trabajo es un aporte importante a los protocolos existentes en la bibliografía en cuanto a los detalles metodológicos en los equipos de angiografía, debido a la generalidad con la que se establece el desarrollo de las pruebas de control de calidad en equipos fluoroscópicos. Además, los fantomas construidos no son muy comunes en el país, debido a sus elevados costos, y son de gran utilidad porque seguirán siendo utilizados en diferentes centros médicos que requieran el servicio de actualización de licencias en la práctica médica, mediante el cual se permite el uso de los equipos emisores de radiación. 


\section{Referencias}

[1] Ministerio de Salud y Protección Social. Resolución 482 "Por la cual se reglamenta el uso de equipos generadores de radiación ionizante, su control de calidad, la prestación de servicios de protección radiológica y se dictan otras disposiciones", Bogotá, 2018.

[2] Sociedad Española de Física Médica, Sociedad Española de Protección Radiológica y Sociedad Española de Radiología Medica, "Protocolo Español de calidad en radiodiagnóstico”. Revisión 2011 (Aspectos Técnicos), 2011, pp. 47-61.

[3] Acuerdo Regional de Cooperación para la Promoción de la Ciencia y la Tecnología Nuclear en Latinoamérica y el Caribe (ARCAL) XLIX, "Implementación de las normas Básicas de Seguridad Internacionales en las Prácticas Médicas, Protocolos de Control de Calidad en Radiodiagnóstico", 2001, pp. 54-71.

[4] M. R. Ruiz. Tablas antropométricas infantiles. Bogotá, Universidad Nacional de Colombia, Facultad de Artes, 2008.

[5] W. R. Hendee, "X rays in medicine", Physics Today, vol. 48, n. ${ }^{\circ} 11$. pp. 48-51, 1995. https://doi.org/10.1063/1.881440

[6] J. E. Turner, "Interaction of Photons with Matter", En Atoms, radiation, and radiation protection. Third
Edition. Wiley-VCH, 2008, pp. 173-177. https://doi. org/10.1002/9783527616978.ch8

[7] E. B. Podgorsak, "Interactions of Photons with Matter", En Radiation physics for medical physicists. Springer-Verlag, 2006, pp. 277-355. https://doi.org/10.1007/978-3642-00875-7

[8] Organismo Internacional de Energía Atómica, Protección radiológica de los pacientes: fluoroscopia [Online]. Disponible en https://rpop.iaea.org/RPOP/RPoP/Content-es/InformationFor/HealthProfessionals/1_Radiology/Fluoroscopy.htm.

[9] A. Brosed (ed.), Fundamentos de física médica. Vol. 2: Radiodiagnóstico: bases físicas, equipos y control de calidad. Madrid : SEFM, Universidad Internacional de Andalucía. 2004, p. 2.

[10] R. Y. L. Chu, J. Fisher, B. R. Archer, B. J. Conway, M. M. Goodsitt, S. Glaze, J. E. Gray, K. J. Strauss, "Standardized Methods for Measuring Diagnostic X-ray Exposures". American Institute of Physics; New York, NY, USA: AAPM Report 31, 1990.

[11]A. Schreiner-Karoussou, "Review of image quality standards to control digital X-ray systems". Radiation Protection Dosimetry, vol. 117, no. 1-3, pp. 23-25, 2005. https:// doi.org/10.1093/rpd/nci722 